\title{
Soybean Cyst Nematode HG Type Test Results Differ Among Multiple Samples from the Same Field but the Management Implications Are the Same
}

\author{
Augustine Q. Beeman, Chelsea J. Harbach, Christopher C. Marett, and Gregory L. Tylka, Department of Plant Pathology and \\ Microbiology, Iowa State University, Ames 50011
}

Accepted for publication 20 June 2016. Published 22 July 2016.

Beeman, A. Q., Harbach, C. J., Marett, C. C., and Tylka, G. L. 2016. Soybean cyst nematode HG type test results differ among multiple samples from the same field but the management implications are the same. Plant Health Prog. 17:160-162.

Growing soybean cultivars that are resistant to the soybean cyst nematode (SCN), Heterodera glycines, is an effective way to preserve soybean yield and limit increases in population densities of the nematode. The ability of SCN populations to reproduce on germplasm lines that are used in soybean breeding programs to develop SCN-resistant cultivars was measured and classified originally by the race test (Golden et al. 1970; Riggs and Schmitt 1988 ) and more recently by the HG type test (Niblack et al. 2002). The "HG" represents the first letters in the genus and species names of SCN, Heterodera glycines. Seven different soybean germplasm lines or cultivars that have been registered in a scientific journal currently are the indicator lines in the HG type test. The indicator lines are assigned index numbers 1 through 7 , and the ability of an SCN population to reproduce on each of the HG type indicator lines is determined by calculating a female index. The female index is the average number of SCN females produced on the HG type indicator line relative to the number produced on a standard, susceptible soybean cultivar in a 30-daylong HG type test conducted in a greenhouse (Niblack et al. 2002).

The results of an HG type test consist of the female index values of the SCN population on the seven HG type indicator soybean lines, and the index numbers of the indicator lines on which the female index is 10 or more are included in the HG type designation of the SCN population. For example, an HG type 1.2.5.7 SCN population would have a female index of 10 or more on indicator lines 1, 2, 5, and 7, which are PI 548402 (Peking), PI 88788, PI 209332, and PI 549319, respectively (Table 1). The indicator line index numbers in the type designation of an SCN population and the actual female index values on the indicator lines provide useful information on how well an SCN population in a field will be managed by a soybean cultivar with the sources of resistance that are the HG type indicator lines used in the test.

The HG type test is conducted on an SCN population obtained from a soil sample collected from a field, not the entire SCN population present in the field. The objective of this study was to determine how HG type test results might vary among SCN populations in independent samples collected from the same field or area of a field.

Corresponding author: G. L. Tylka. Email: gltylka@iastate.edu.

\section{VARIATION AMONG SAMPLES COLLECTED FROM 0.8} ACRE

A composite soil sample was obtained from a 0.8-acre (0.3-ha) area of a 150-acre (60.7-ha) field (Fig. 1) in Nevada, IA, for HG type testing of the SCN population. Research experiments had not been conducted in the field prior to 2008 , and a soybean cultivarevaluation experiment was planted in the 0.8 -area of the field in May 2008. Ten 1-inch-diameter, 8-inch-deep soil cores were collected from the center two rows of each 4-row-wide by 17-feet (5.2- $\mathrm{m})$ long plot in the experiment at the time of planting. The ten soil cores from an individual plot were combined to comprise

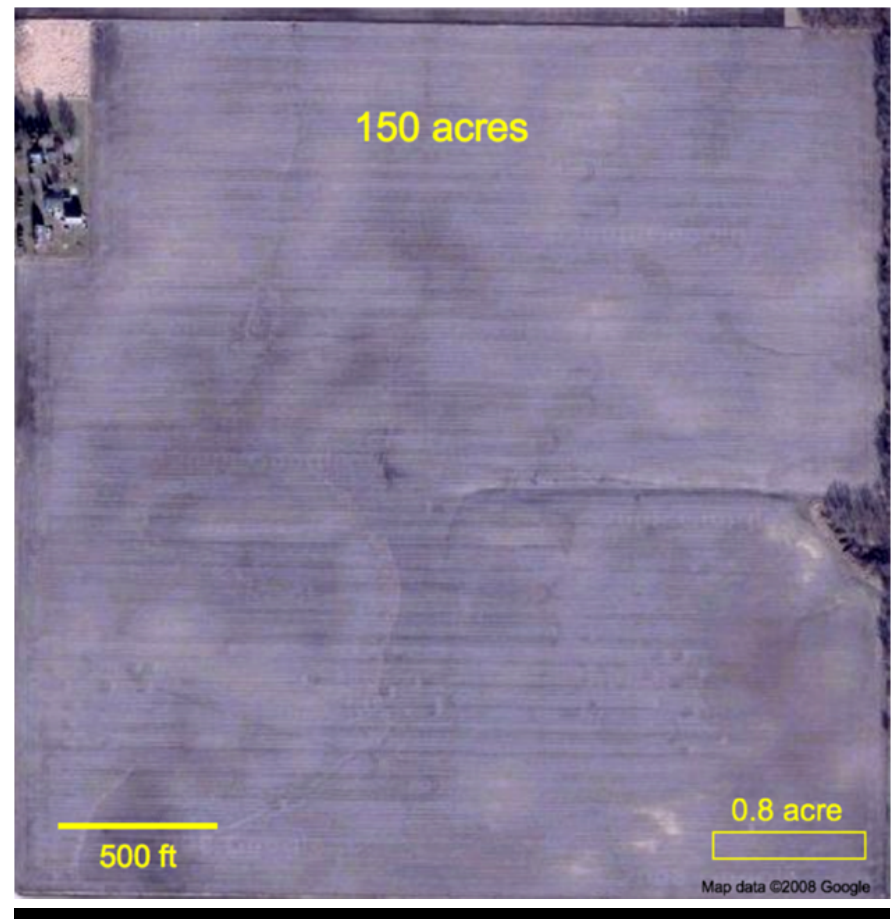

FIGURE 1

An aerial image of the field near Nevada, IA, where HG type test samples were collected. In 2008, five independent soil samples were taken in the 0.8-acre (0.3-ha) area outlined at the bottom right of the field image. In 2009, samples were collected from nine arbitrarily selected, non-overlapping, 10-acre (4-ha) areas in the 150-acre (60.7ha) field. 
a single sample from which the SCN egg population density was determined for the plot (data not shown). After the SCN population densities were determined, the leftover soil remaining from the samples collected from all 132 plots was combined and mixed thoroughly to create the composite sample for HG type testing. Four additional, independent 100-core soil samples were collected from within the same 0.8 -acre area of the field four weeks after planting. The soil cores were 1 inch $(2.5 \mathrm{~cm})$ in diameter and 8 inches $(20 \mathrm{~cm})$ deep and were collected in an arbitrary zig-zag pattern from the entire area. All 100 soil cores were combined to comprise a single, independent soil sample from the 0.8-acre area. The composite sample from the plots collected at the time of planting plus the four additional 100-core samples from the same 0.8 -acre plot area were sent to the University of Missouri Plant Nematology Laboratory where HG type tests were performed. A susceptible soybean cultivar was grown in each of the soil samples for 30 days in a water bath at $81^{\circ} \mathrm{F}\left(27^{\circ} \mathrm{C}\right)$ in a greenhouse to increase the population densities of the nematode, and then eggs were extracted from SCN females recovered from the roots and used in the HG type test as described by Niblack et al. (2002)

The HG type of the SCN population in the composite soil sample collected from the 132 plots in the 0.8 -acre area was 1.2.5.6.7 (Table 1). This HG type designation was different from the HG type in any of the four 100-core soil samples collected. The SCN population in two of the four 100-core samples was type 1.2.5.7 and other two were type 1.2.3.5.6.7 (Table 1).

The variability in the results from the five samples of 100 or more soil cores collected from such a small area ( 0.8 acre) of a field may seem large because three different $\mathrm{HG}$ types were identified. But the female indices for the SCN populations all were above or below the critical value of 10 for five of the seven HG type indicator soybean lines (1, 2, 4, 5, and 7), so the HG type designation was consistent for those five HG type indicator lines.

Among the SCN populations in the five samples, the least amount of variability in female indices occurred on the PI 437654 indicator line (all female indices were 0 ) and greatest amount on PI 209332 (female indices ranged from 37 to 59) (Table 1). The highest female indices were on PI 548316. The ranges of female indices on PI 90763 and PI 89772 were relatively small, from 3 to 12 and from 4 to 15 , respectively, but indicator line index numbers 3 and 6 do not appear in all of the HG type designations for the samples because the variation in female indices spanned the critical value of 10 .

Despite having three different HG types identified among the five samples, the management implications from the results are identical. The results indicated that there would be more SCN reproduction on resistant soybean cultivars with the Peking, PI 88788, PI 209332, and PI 548316 sources of SCN resistance than cultivars with PI 90763, PI 437654, and PI 89772 SCN resistance in the area of the field that was sampled. Consequently, soybean cultivars with the PI 90763, PI 437654, and PI 89772 sources of $\mathrm{SCN}$ resistance would be most effective for managing $\mathrm{SCN}$ in the sampled area if such cultivars were available.

\section{VARIATION AMONG SAMPLES COLLECTED FROM 150 ACRES}

In April of 2009, independent, 100-core soil samples were collected from nine arbitrarily defined, non-overlapping, 10-acre (4-ha) areas within the same 150-acre field that was sampled in 2008 (Fig. 1) to determine the variability in HG type test results at different locations throughout a single field. The 10-acre areas that were sampled did not include the 0.8 -acre area sampled in 2008, and all nine soil samples were collected on the same day, prior to corn being planted in the field. The samples were submitted to the University of Missouri Plant Nematology Laboratory for HG type determination using the same procedures that were used in 2008.

Among the SCN populations in the nine samples, there were three different $\mathrm{HG}$ type designations: types 7, 2.7, and 2.5.7 (Table 2). Overall, the SCN female indices were lower for the SCN populations in the samples collected in 2009 than for the populations in the samples collected from the much smaller area in 2008. But the range of female indices on several of the HG type indicator lines was greater for the SCN populations in the samples collected in 2009 (Table 2) than those in samples collected in 2008 (Table 1). The least amount of variability in female indices of the SCN populations in samples collected in 2009 occurred on PI 437654 (female indices were all 0), and the greatest amount of variability was on PI 548316 (female indices ranged from 19 to 50), which also had the highest female index values. Female indices spanned the critical value of 10 on HG type indicator soybean lines PI 88788 and PI 209332, resulting in the indicator line index numbers 2 and 5, respectively, not appearing consistently in all of the HG type designations of the SCN populations in the samples collected in 2009.

Although different HG types were identified for the SCN populations in the nine samples collected in 2009, the management implications were the same, just as occurred with the SCN populations from the five soil samples collected in 2008. The HG type test results in 2009 indicated that SCN-resistant soybean cultivars with resistance genes from PI 88788, PI 209332, and PI 548317 would not be as effective at inhibiting reproduction of SCN in the field as cultivars with the other four sources of resistance, if such cultivars were available.

As mentioned above, the female indices were notably higher on almost all of the HG type indicator lines for the SCN populations in the soil samples collected in 2008 (Table 1) than in 2009 (Table

\begin{tabular}{|c|c|c|c|c|c|c|c|c|}
\hline \multirow[b]{3}{*}{ Sample \# } & $\begin{array}{l}\text { dices and } \\
\text { numberec }\end{array}$ & $\begin{array}{l}\text { ype desigr } \\
\text { 4) and or }\end{array}$ & $\begin{array}{l}\text { ons for SC } \\
\text { omposite } \\
\text { of a fie }\end{array}$ & $\begin{array}{r}\text { TABLE } 1 \\
\text { ppulations } \\
\text { ple collect } \\
\text { ear Nevada }\end{array}$ & $\begin{array}{l}\text { ur indepen } \\
\text { om } 132 \text { plo } \\
\text { in } 2008 \text {. }\end{array}$ & $\begin{array}{l}100 \text {-core } \\
\text { a } 0.8 \text {-acr }\end{array}$ & $\begin{array}{l}\text { samples (a } \\
\text { 3-ha) area }\end{array}$ & rarily \\
\hline & \multicolumn{7}{|c|}{ Female Index (percent reproduction relative to susceptible) } & \multirow[b]{2}{*}{$\begin{array}{l}\text { HG } \\
\text { Type }\end{array}$} \\
\hline & $\begin{array}{c}\# 1 \\
\text { PI 548402 } \\
\text { (Peking) }\end{array}$ & $\begin{array}{c}\text { \#2 } \\
\text { PI } 88788\end{array}$ & $\begin{array}{c}\# 3 \\
\text { PI } 90763\end{array}$ & $\begin{array}{c}\# 4 \\
\text { PI } 437654\end{array}$ & $\begin{array}{c}\# 5 \\
\text { PI } 209332\end{array}$ & $\begin{array}{c}\# 6 \\
\text { PI } 89772\end{array}$ & $\begin{array}{c}\# 7 \\
\text { PI } 548316 \\
\text { (Cloud) }\end{array}$ & \\
\hline 1 & 38 & 55 & 8 & 0 & 50 & 5 & 66 & 1.2.5.7 \\
\hline 2 & 37 & 45 & 3 & 0 & 45 & 4 & 63 & 1.2 .5 .7 \\
\hline 3 & 43 & 58 & 12 & 0 & 42 & 14 & 67 & 1.2.3.5.6.7 \\
\hline 4 & 44 & 53 & 10 & 0 & 59 & 15 & 68 & 1.2 .3 .5 .6 .7 \\
\hline composite & 44 & 54 & 9 & 0 & 37 & 14 & 63 & 1.2 .5 .6 .7 \\
\hline range & 7 & 13 & 9 & 0 & 22 & 11 & 5 & - \\
\hline
\end{tabular}




\begin{tabular}{|c|c|c|c|c|c|c|c|c|}
\hline \multicolumn{9}{|c|}{$\begin{array}{l}\text { TABLE } 2 \\
\text { Female indices and HG type designations for SCN populations in nine independent 100-core soil samples (arbitrarily } \\
\text { numbered } 1 \text { to 9) collected from nine arbitrarily selected, non-overlapping, 10-acre (4-ha) areas } \\
\text { in a 150-acre (60.7-ha) field located near Nevada, IA, in } 2009 .\end{array}$} \\
\hline \multirow[b]{2}{*}{ Sample \# } & \multicolumn{7}{|c|}{ Female Index (percent reproduction relative to susceptible) } & \multirow[b]{2}{*}{$\begin{array}{c}\text { HG } \\
\text { Type }\end{array}$} \\
\hline & $\begin{array}{c}\# 1 \\
\text { PI 548402 } \\
\text { (Peking) }\end{array}$ & $\begin{array}{c}\text { \#2 } \\
\text { PI } 88788\end{array}$ & $\begin{array}{c}\# 3 \\
\text { PI } 90763\end{array}$ & $\begin{array}{c}\# 4 \\
\text { PI } 437654\end{array}$ & $\begin{array}{c}\# 5 \\
\text { PI } 209332\end{array}$ & $\begin{array}{c}\# 6 \\
\text { PI } 89772\end{array}$ & $\begin{array}{c}\# 7 \\
\text { PI 548316 } \\
\text { (Cloud) }\end{array}$ & \\
\hline 1 & 0 & 9.9 & 0 & 0 & 9.6 & 0 & 26 & 7 \\
\hline 2 & 2 & 6 & 0 & 0 & 4 & 0 & 26 & 7 \\
\hline 3 & 0 & 8 & 0 & 0 & 5 & 1 & 20 & 7 \\
\hline 4 & 0 & 29 & 0 & 0 & 30 & 0 & 50 & 2.5 .7 \\
\hline 5 & 2 & 10 & 1 & 0 & 7 & 1 & 33 & 2.7 \\
\hline 6 & 1 & 13 & 1 & 0 & 9.9 & 2 & 48 & 2.7 \\
\hline 7 & 1 & 14 & 0 & 0 & 11 & 0 & 42 & 2.5 .7 \\
\hline 8 & 1 & 8 & 3 & 0 & 6 & 1 & 19 & 7 \\
\hline 9 & 2 & 14 & 2 & 0 & 6 & 0 & 41 & 2.7 \\
\hline range & 2 & 23 & 3 & 0 & 26 & 2 & 31 & - \\
\hline
\end{tabular}

2). The cause of the difference in the results is not clear. The two sets of samples were collected 10 to 11 months apart and were collected following different crops. The 2008 samples were collected following corn that was grown in the field in 2007 whereas the 2009 samples followed an SCN-resistant soybean cultivar with PI 88788 resistance that was grown in the field in 2008. The preceding crop may have affected the magnitude of the female indices on the HG type indicator lines, but there is no report of such an effect in the scientific literature. Despite having different female index values in the SCN populations obtained from the samples collected in 2008 and 2009, the results obtained from both sets of samples revealed that HG type designations and female indices may vary among samples from a defined area, but the implications for management of SCN are the same.

\section{SUMMARY}

To obtain the most meaningful information from an HG type test on an SCN population in a field, a soil sample comprising 100 or more soil cores should be collected from throughout all areas of a field. Samples composed of more than 100 cores may be particularly justified for large fields. The results presented herein indicate that there is likely no benefit to collecting and having HG types determined on SCN populations in multiple independent soil samples from different areas of the field. Our work shows that the results of an HG type test can vary among SCN populations captured in multiple soil samples collected from a single field (or small area of a field), but the implications of multiple test results for managing the nematode are the same with respects to selecting and growing SCN-resistant soybean cultivars.

Most of the SCN-resistant soybean cultivars currently available to farmers have SCN resistance genes from PI 88788 (Tylka and Mullaney 2015). So the female index on PI 88788 is particularly important information obtained from an HG type test. The female index can be thought of as somewhat of an aggressiveness index for the SCN population (Tylka 2016) because the female index indicates how well the SCN population will reproduce on, and thereby cause damage to, resistant soybean cultivars with the sources of resistance that are the indictor lines used in the $\mathrm{HG}$ type test.

It is important to understand that the variation in HG type designations and in the female indices of SCN populations in multiple samples collected from the same areas in our research were not the result of different SCN strains or isolates mixing or co-infesting the areas that were sampled. The different HG type designations and the differences in female indices of the SCN populations in the samples were the result of variation in the frequency of occurrence of individuals in the SCN population with specific parasitic abilities present in the samples. The SCN HG type (and race) designation and accompanying female indices for the various HG type indicator lines provide an overall indication of the virulence phenotype or parasitic capabilities of an SCN population present in a field. Individual nematodes either can or cannot reproduce on each individual HG type indicator line, and it is the combined frequencies of occurrence of nematodes with varying parasitic capabilities that define the HG type designation in SCN populations (Tylka 2016).

\section{LITERATURE CITED}

Golden, A. M., Epps, J. M., Riggs, R. D., Duclos, L. A., Fox, J. A., and Bernard, R. L. 1970. Terminology and identity of infraspecific forms of the soybean cyst nematode (Heterodera glycines). Plant Dis. Rep. 54:544-546.

Niblack, T. L., Arelli, P. R., Noel, G. R., Opperman, C. H., Orf, J. H., Schmitt, D. P., Shannon, J. G., and Tylka, G. L. 2002. A new classification scheme for genetically diverse populations of Heterodera glycines. J. Nematol. 34:279-288.

Riggs, R. D., and Schmitt, D. P. 1988. Complete characterization of the race scheme for Heterodera glycines. J. Nematol. 20:392-395.

Tylka, G. L. 2016. Understanding soybean cyst nematode HG types and races. Plant Health Prog. 17:149-151. doi:10.1094/PHP-PS-16-0615.

Tylka, G. L., and Mullaney, M. P. 2015. Soybean cyst nematode-resistant soybeans for Iowa. Ext. Publ. PM 1649. Iowa State Univ., Ames. 